\title{
Prediction of flow and dispersion in cross-ventilated buildings
}

\author{
Ali Cemal Benim*, Michael Diederich, and Ali Nahavandi
}

Center of Flow Simulation (CFS), Department of Mechanical and Process Engineering, Düsseldorf University of Applied Sciences, Münsterstr. 156, D-40476 Düsseldorf, Germany

\begin{abstract}
The present paper presents a detailed computational analysis of flow and dispersion in a generic isolated single-zone buildings. First, a grid generation strategy is discussed, that is inspired by a previous computational analysis and a grid independence study. Different turbulence models are applied including two-equation turbulence models, the differential Reynolds Stress Model, Detached Eddy Simulation and Zonal Large Eddy Simulation. The mean velocity and concentration fields are calculated and compared with the measurements. A satisfactory agreement with the experiments is not observed by any of the modelling approaches, indicating the highly demanding flow and turbulence structure of the problem.
\end{abstract}

\section{Introduction}

Natural convection is an important feature in the development of energy-efficient and healthy indoor environment [1]. This is driven either by buoyancy, or wind or by their combination [2]. In the past, many investigations were performed for evaluating the natural ventilation performance of buildings. Extensive reviews on techniques for assessing building ventilation assessment were provided by several researchers [3]. For assessing the ventilation performance, experimental [4], analytical and semi-empirical methods were used [5], along with zonal and multi-zone network models [6]. A number of investigations based on Computational Fluid Dynamics (CFD) were also presented [7].

In relationship with the modeling of pollutant dispersion, a large body of literature exists for dispersion in the outdoor [8] and indoor [9] environment. Studies were also performed on dispersion between different indoor environments due to natural ventilation, many of them being motivated by the SARS threat [10]. A number of studies analyzed the pollutant dispersion in cross-ventilated buildings using numerical or experimental methods, with emphasis on greenhouses or livestock buildings, like, e.g. the studies of Bartzanas et al. [11] and Norton et al. [12], who applied twodimensional and three-dimensional, as well as steady and unsteady Reynolds Averaged Numerical Simulations (RANS). Van Hoof and Blocken [13] measured and calculated (unsteady RANS) the dispersion of $\mathrm{CO}_{2}$ by natural cross-ventilation in a large stadium.

Tominaga and Blocken [14] presented a comprehensive review of the previous work in the field, as also outlined above, and identified that the previous work is almost exclusively about case studies, and there is a lack of experimental as well as numerical studies of cross-ventilation with indoor dispersion for generic building configurations. Given this, Tominaga and
Blocken [14] performed detailed measurements of flow and dispersion on cross-ventilated buildings in an atmospheric boundary layer wind tunnel, as a continuation of their previous paper [15], emphasizing the importance of these detailed measurements for a better understanding of the dispersion process and as data for CFD validation studies. The latter is the scope of the present study. The measurements [14] are taken as the data base to validate the CFD analyses, in particular, with respect to the applied turbulence modelling.

\section{Modelling}

Three-dimensional, turbulent flow of the air-gas mixture is modelled as incompressible, as the Mach numbers have been very low. The modelling is performed within the framework of the general-purpose CFD software ANSYS Fluent 18.0 [16]. Turbulence is modelled by different approaches. In the first category, Reynolds Averaged Numerical Simulation (RANS) approach is applied, in combination with different turbulence models. As the turbulent viscosity based RANS models, the Standard k- $\varepsilon$ model [16-19], the RNG k- $\varepsilon$ model $[16,20]$, the Realizable $\mathrm{k}-\varepsilon$ model $[16,21]$, as well as the SST k- $\omega[16,22,23]$ model are applied. Additionally, the Reynolds Stress Model (RSM) [16,24] is also used, based on the dissipation rate of the turbulence kinetic energy dissipation to obtain the length scale information, while using the linear [25] and quadratic [26] pressurestrain models.

As more sophisticated modelling strategies Detached Eddy Simulation (DES) and Large Eddy Simulation (LES) [16,27-32] are applied. In DES, as the URANS counterpart, the Realizable k- $\varepsilon$ and the SST k- $\omega$ models are used. LES is applied in terms of a zonal approach, where the LES approach within the internal domain, using WALE as the subgrid scale model $[16,31,32]$ is

\footnotetext{
* Corresponding author: alicemal@prof-benim.com
} 
coupled with URANS (Realizable k- $\varepsilon$ model) and in the outer domain. The near-wall turbulence is modelled by the so-called enhanced wall treatment $[16,33,34]$ for the $\mathrm{k}-\varepsilon$ and linear pressure-strain RSM models, whereas the blending used in the k- $\omega$ model [16] may be considered to be comparable the enhanced wall treatment. For the quadratic pressure-strain RSM, scalable wall-functions [16] are used. For LES, standard wall functions [16] are used near the wall.

For the velocity-pressure coupling, the SIMPLEC [16] and PISO [16] schemes are used for steady-state and unsteady formulations, respectively. For unsteady calculations, a second-order accurate differencing scheme is used for time discretization [16]. For LES and DES, a Bounded Second Order Implicit scheme [16] is used in time. In all cases, the time step-size is selected to assure the cell Courant number to be smaller than unity. For the discretization of convective terms, the formally third-order accurate QUICK scheme [16] is used for all equations and cases, with the following exceptions: Applying the RSM, the Power Law scheme [16] is used for the transport equations of the Reynolds stresses. Additionally, in applying LES and DES, the Bounded Central Differencing scheme is used for the momentum equations. In all cases grid studies are performed, considering resolution aspects related to LES $[35,36]$.

\section{The test case}

As discussed above, the experimentally investigated cases of Tominaga and Blocken [14] are considered. In that study [14], five generic isolated single-zone buildings were considered, each with two opposite openings, in the windward and leeward façade. One of them (Configuration E [14]) is considered in the present study This configuration is similar to those, previously used in the experimental studies of Karava et al. [37] and numerical studies of Meroney [38] as well as Ramponi and Blocken $[39,40]$. The wind direction was selected as perpendicular to the openings [14]. Measurements were performed at the atmospheric boundary layer wind tunnel at Niigata Institute of Technology, which has a 13 $\mathrm{m}$ long test section and a cross-section of $1.8 \times 1.8 \mathrm{~m}^{2}$. Details of the measurements are provided in [14].

The model building geometry is sketched in Figure 1, indicating the gas opening $\left(8 \times 8 \mathrm{~mm}^{2}\right)$ on the floor $(\mathrm{d}=8 \mathrm{~mm})$, for Ethylene $\left(\mathrm{C}_{2} \mathrm{H}_{2}\right)$ injection The width $(\mathrm{W})$, depth (D) and height $(\mathrm{H})$ of the model are $200 \mathrm{~mm}$, $200 \mathrm{~mm}$ and $160 \mathrm{~mm}$, respectively, corresponding to a 1:100 model of a $20 \times 20 \times 16 \mathrm{~m}^{3}$ building.

\section{Solution domain, boundary conditions}

The wind tunnel size is quite large compared to that of the centrally spaced model building (Fig. 1), so that a sufficiently large computational domain around the building can be defined to be representative, without touching the physical boundaries (walls) of the wind tunnel on the sides and on the top. For the computational domain size, the best practice guidelines by Tominaga et al. [41] are applied, apart from the upstream length,

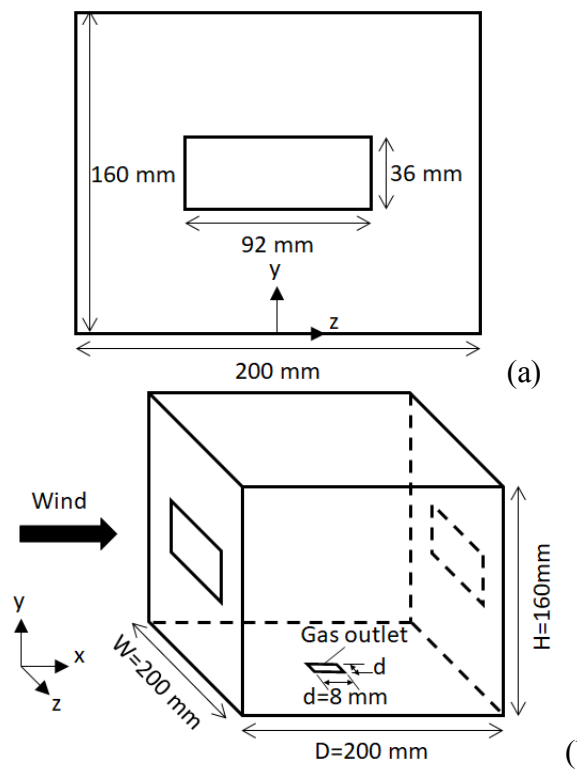

(b)

Figure 1. Sketch of building (a) front view, (b) persp. view [14]

which is reduced to three times the height $(\mathrm{H})$ of the building, to limit the development of unintended streamwise gradients, following the suggestion of Ramponi and Blocken [40]. Thus, the upstream (inlet) and downstream (outlet) boundaries of the solution domain are placed at a distance $3 \mathrm{H}$ and $15 \mathrm{H}$ from the building, respectively. The upper and the two side boundaries of the domain are placed, each, at a $5 \mathrm{H}$ distance apart from the building. The boundaries on the top and the sides are defined to be symmetry planes. At the downstream boundary, the static pressure is prescribed along with zero normal gradients for the remaining variables. At the inlet of the channel, a parallel, boundary layer flow is assumed, where the time-averaged streamwise velocity $(\mathrm{u})$ is prescribed according to the following expression, which was found [14] to represent the measured velocity profile very well.

$$
\frac{\mathrm{u}}{\mathrm{U}_{\mathrm{H}}}=\left(\frac{\mathrm{y}}{\mathrm{H}}\right)^{0.25}
$$

For the turbulence kinetic energy (k), the following profile is applied at the inlet, which is, again, suggested based on the measurements [14].

$$
\frac{\mathrm{k}}{\mathrm{U}_{\mathrm{H}}^{2}}=0.033 \exp \left(-0.32\left(\frac{\mathrm{y}}{\mathrm{H}}\right)\right)
$$

In Eqns. $(1,2), \mathrm{U}_{\mathrm{H}}$ denotes the time-averaged streamwise velocity component at the reference height $H$ [14]. Different $U_{H}$ values were used in [14] i.e. $4.3 \mathrm{~m} / \mathrm{s}$ and $2.2 \mathrm{~m} / \mathrm{s}$ yielding building Reynolds numbers of about 45,000 and 23,000 , respectively. The smaller value $\left(\mathrm{U}_{\mathrm{H}}=2.2 \mathrm{~m} / \mathrm{s}\right)$ was used for the traversal concentration measurements. For deriving the boundary conditions of the dissipation rate $(\varepsilon)$ and the specific dissipation rate $(\omega)$, a length scale information is needed. This is assumed to be given by the following empirical distribution [42]

$$
1_{\mathrm{m}}=\min (\kappa \mathrm{y}, \mathrm{C} \delta)
$$


for Prandtl's mixing length $\left(1_{\mathrm{m}}\right)$, with $\kappa=0.41$ (von Karman's constant), $\mathrm{C}=0.09, \delta$ denoting the boundary layer thickness, which is taken as the half of the channel height. For the RSM, the inlet boundary conditions for the Reynolds stresses are derived assuming a locally isotropic turbulence with vanishing shear stresses.

For the pollutant gas injection through the opening on the building's floor (Fig. 1), the bulk jet inlet velocity is $\mathrm{V}_{\mathrm{J}}=0.52 \mathrm{~m} / \mathrm{s}$, which is applied as boundary condition, assuming a top-hat profile. The comparably low velocity results in a rather low Reynolds number at the jet exit. This is approx. 500, based on the jet diameter (d), indicating a locally rather laminar flow. Thus, the inlet values of the turbulence quantities are set to very low values (e.g. turbulence intensity $0.1 \%$ ) at the jet inlet.

\section{Grid generation}

Ramponi and Blocken [40] investigated a very similar problem, with the same topology. Besides the different model building size, the main difference of [40] to the present case resides in that fact that in [40], only the aerodynamics was investigated, without considering gas injection. In the present study, first, a block-structured grid is generated, as the baseline grid, which is very similar to that of [40] consisting of 576,936 cells. Since it was reported in [40] that grid independent results were obtained with 575,247 cells for the same topology, it is assumed that this grid also provides a sufficient grid independence for the present case, for a situation without the gas injecting central jet (which was missing on [40]). A detail, perspective view of the surface grid of the generated baseline grid is presented in Figure 2.

In the present problem, an additional feature is the injection of gas by a jet through a central opening at the building's floor. It is assumed that the baseline grid can be improved by local grid refinements to provide an adequate resolution to consider central jet. The grid refinements are performed by means of structured refinements, which are "isotropic" (i.e. by halving the cells in all three directions), locally, within hexahedral sub-domains of the original grid, resulting in nonconformal interfaces to the parent grid. In these grid independence studies the Standard k- $\varepsilon$ model is used. Three levels of grid refinement are applied. The first refinement is performed in a domain enclosing the building. The borders of the domain are placed at a distance of $0.1 \mathrm{D}$ to the building walls (Grid 2, with $1,147,466$ cells). The second refinement was performed in a smaller region of size $4 \mathrm{~d} \times 4 \mathrm{~d} \times 4 \mathrm{~d}$, in the building, in the vicinity of the jet inlet (the jet inlet being placed at the middle of the lower face of the hexahedral refinement domain) (Grid 3, with 1,169,986 cells). A third refinement is performed for a smaller region around the jet inlet with size $2 \mathrm{~d} \times 2 \mathrm{~d} \times 2 \mathrm{~d}$ (Grid 4, with $1,176,026$ cells). Although the total number of cells are not varying very strongly between the Grids 2,3 , and 4, the improvement of the discretization in the jet nearfield is remarkable, as the refinement is performed locally.

Before checking grid independence by considering the central jet, for confirming the assumed grid

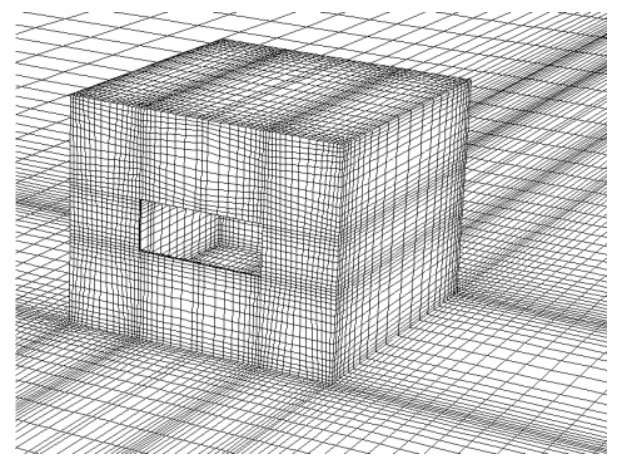

Figure 2. Perspective view of the baseline grid (Grid 1).

independence by Grid 1 for the case without an internal gas jet, the variations of the mean velocity along the horizontal line extending between the middle points of the both openings as calculated by Grid 1 and Grid 2 are compared in Figure 3. The rather small deviation confirms the adequacy of Grid 1 as the baseline grid.

For assessing the grid resolution for an adequate account of the jet injection, the jet penetration is monitored. Please note that the expected jet penetration is quite low, due to the comparably low jet velocity. The mean vertical velocity component (v), nondimensionalized by the jet exit velocity $\mathrm{V}_{\mathrm{J}}$, as calculated by different grids, is plotted along a vertical line ( $\mathrm{y}$ direction) emerging from the jet inlet, in Figure 4. One can see that Grids 2-4 agree quite well with each other. The Grid 4, with 1,176,026 cells is taken as the grid for the further analysis.

\section{Results}

The results for the axial velocity (axial velocity: velocity component in the $\mathrm{x}$ direction, i.e. the main flow direction) obtained bv the RANS-RSM are compared with the experiments [14] in Figure 5. The figure shows the variation of normalized axial velocity variation along a vertical line emerging from the middle point $(\mathrm{x}=\mathrm{z}=0)$ of the jet. One can see that the RSM results don't agree very well either with the experiments or with each other.

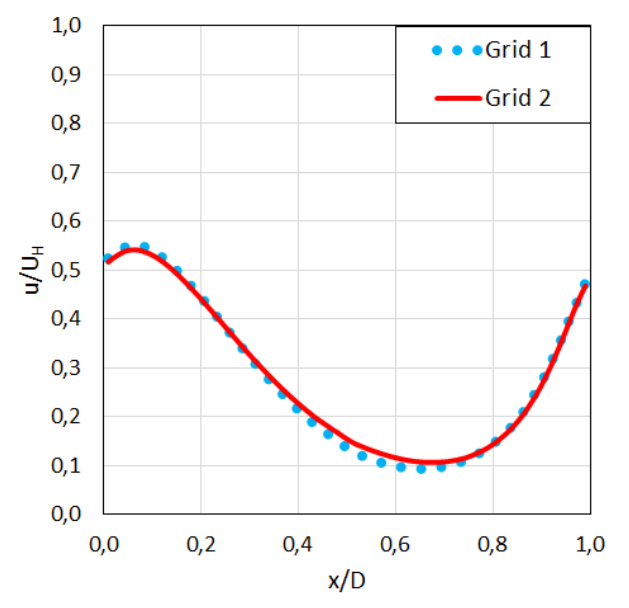

Figure 3. Variation of predicted time-averaged axial velocity using two grids, along a horizontal line extending the between the middle points of the openings. 


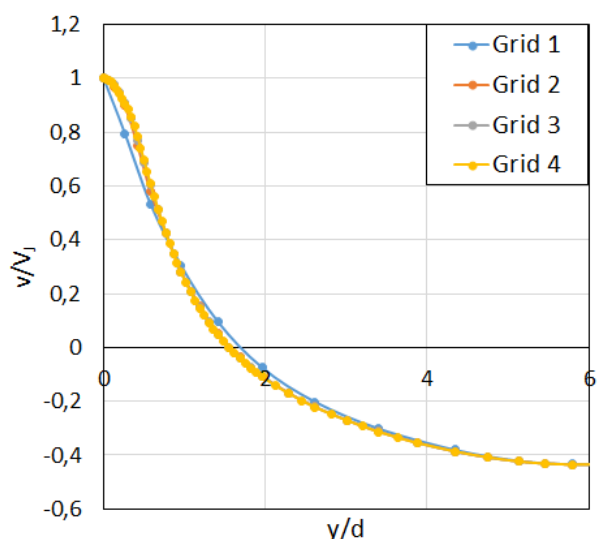

Figure 4. Variation of predicted time-averaged vertical velocity using four grids, along a vertical line emerging from the middle point of the jet inlet.

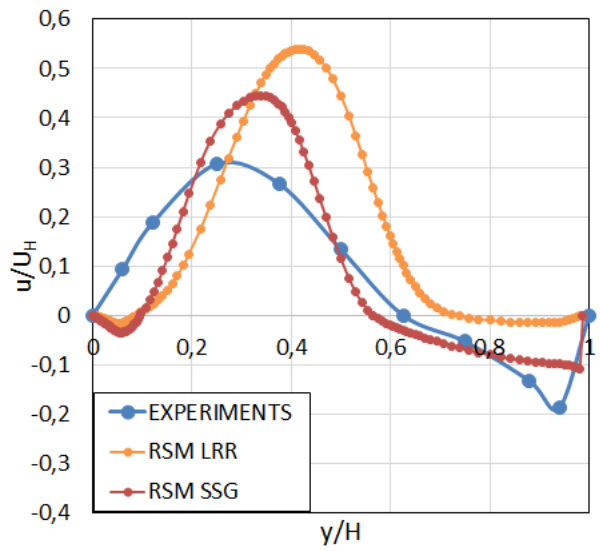

Figure 5. Variation of time-averaged axial velocity, along a vertical line emerging from the middle point of the jet inlet (RANS-RSM results vs. Experiments).

Due to the rather inferior performance or the RANSRSM, they are not included in the further comparisons. The RANS predictions by the turbulence viscosity models are compared with experiments in Figure 6, where profiles of the normalized axial velocity along a vertical line emerging from the middle point of the jet inlet are shown. One can see that also turbulence viscosity based models do not show a very good agreement with the experiments and with each other. The Standard k- $\varepsilon$ model shows a slightly better agreement with the experiments in predicting the peak value. The Realizable k- $\varepsilon$ model shows a better agreement at with experiments at higher values $\mathrm{y} / \mathrm{H}(\mathrm{y} / \mathrm{H}>0.6)$ in predicting the recirculation (Fig. 6).

The variation of the predicted (RANS, turbulence viscosity models) concentration (c) is compared with the measured values in Figure 7. In the figure, the normalized concentration $\left(\mathrm{C}_{0}=\mathrm{q}_{\mathrm{e}} / \mathrm{H}^{2} \mathrm{U}_{\mathrm{H}}, \mathrm{q}_{\mathrm{e}}\right.$ : pollutant emission rate) is plotted along the initial portion of the previously considered vertical line. One can see that the dispersion of the pollutant is underpredicted by all models. The Realizable k- $\varepsilon$ and the k- $\omega$ SST models can be observed to show a slightly better performance.

The time-averaged axial velocity predicted by DES and LES approaches are compared with experiments in

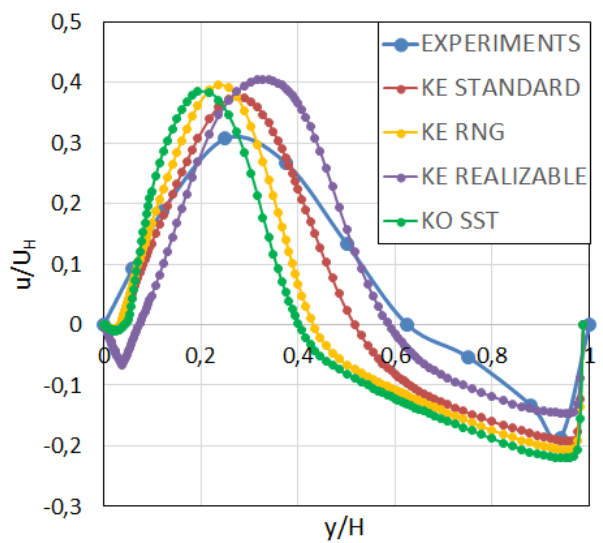

Figure 6. Variation of time-averaged axial velocity, along a vertical line emerging from the middle point of the jet inlet (RANS turbulent vis. model vs. Experiments).

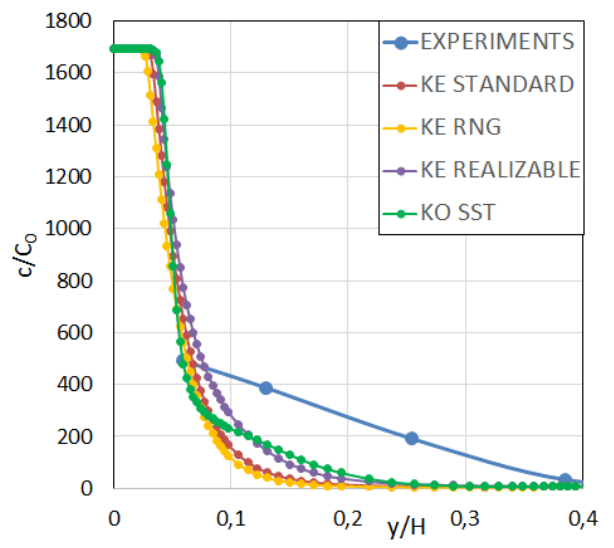

Figure 7. Variation of time-averaged concentration, along a vertical line emerging from the middle point of the jet inlet (RANS turbulent vis. model vs. Experiments).

Figure 8 , where the profiles along the vertical line emerging from the center of the jet are plotted. The predictions are quite close to each other, more than it was the case for RANS (Fig. 6). This can be seen as a reciprocal confirmation of the models. However, their agreement with the measurements is not satisfactory.

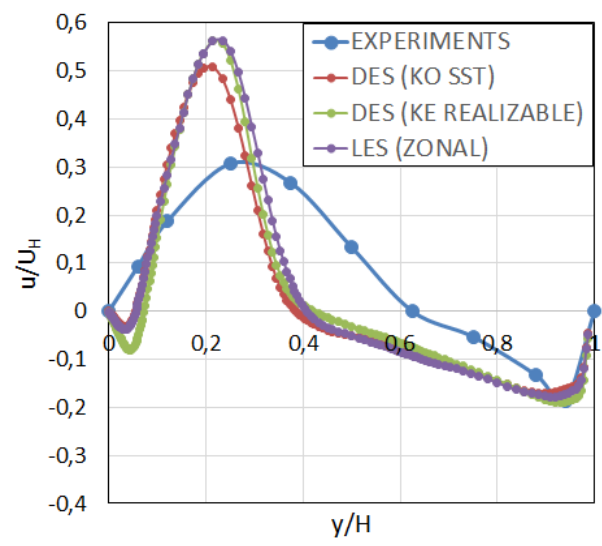

Figure 8. Variation of time-averaged axial velocity, along a vertical line emerging from the middle point of the jet inlet (DES \& LES results vs. Experiments). 
The peak value is substantially overpredicted, along with an underprediction of the traversal expansion of the jet.

The time-averaged concentration predicted by DES and LES approaches are compared with measurements in Figure 9, where the profiles are plotted along the initial part of the vertical line starting from the jet center. One can see that three predictions agree very well with each other, but not with the experiments. The predictions are similar to those obtained by the RANS (Fig. 7).

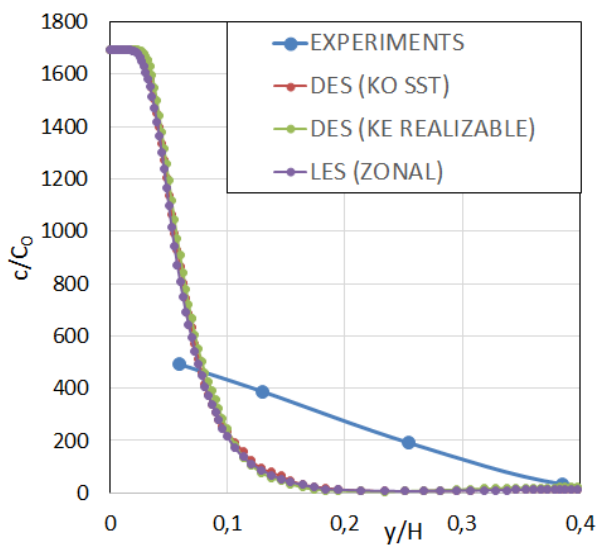

Figure 9. Variation of time-averaged concentration, along a vertical line emerging from the middle point of the jet inlet, for (DES \& LES results vs. Experiments).

\section{Conclusions}

Flow and dispersion in a model isolated building is investigated employing RANS, DES and LES turbulence modelling strategies. Within RANS, along with RSM with linear and quadratic pressure-strain formulations, turbulence viscosity models such as Standard, RNG, Realizable k- $\varepsilon$ and the SST k- $\omega$ are used. DES is applied in combination with the Realizable $\mathrm{k}-\varepsilon$ model and the SST k- $\omega$ model. LES is applied with a zonal strategy, combining the LES solution based on the WALE subgrid scale model with Realizable $\mathrm{k}-\varepsilon$ model in the outer domain. It was observed that none of the models provided a satisfactory agreement with the measurements. RANS models showed substantial variations from each other in each category (RSM and turbulent viscosity), indicating the high sensitivity of the problem as far as the turbulence modelling is concerned. The principally more accurate DES and LES results agreed well with each other, but not provided an improvement in the agreement with the measurements, which was an unexpected behavior. The results show that the problem is very demanding as far as the turbulence modelling is concerned. Strategies for an improved agreement with the experiments will be considered in the future work.

\section{References}

1. M.J. Finnegan, C.A. Pickering, P.S. Burge, "The sick building syndrome: prevalence studies", Br. Med. J. (Clin. Res. Ed.), 289, pp.1573-1575 (1984)
2. P. F. Linden, "The fluid mechanics of natural ventilation”,Annu.Rev.Fluid Mech., 31,pp.201-238 (1999)

3. D.W. Etheridge, Natural Ventilation of Buildings: Theory, Measurement and Design, (John Wiley \& Sons, Chichester, New York, USA, 2011)

4. P. Karava, T. Stathopoulos, "Wind-induced internal pressures in buildings with large façade openings", J. Eng. Mech., 138(4), pp. 358-370 (2012)

5. P. Karava, T. Stathopoulos, A.K. Athienitis, "Wind driven flow through openings-a review of discharge coefficients", Int. J. Vent, 3, pp. 255-266 (2004)

6. J.L.M. Hensen, R. Lamberts, Building Performance Simulation for Design and Operation (Routledge, London, UK. 2011).

7. T. van Hoof, B. Blocken, "On the effect of wind direction and urban surroundings on natural ventilation of a large scale semi-enclosed stadium", Comput. Fluids, 39, pp. 1146-1155 (2010)

8. B. Blocken, Y. Tominaga, T. Stathopoulos, "CFD simulation of micro-scale pollutant dispersion in the built environment”,Build.Env.,64,pp.225-230 (2013)

9. N.P. Gao, J.L. Niu, "Modeling particle dispersion and deposition in indoor environments", Atmos. Environ., 41(18), pp. 3862-3876 (2007)

10. J. Mao, N. Gao, "The airborne transmission of infection between flats in high rise residential buildings: a review”, Build.Environ.,9,pp.516-531 (2015)

11. T. Bartzanas, C. Kittas, A.A. Sapounas, C. NikitaMartzopoulou, "Analysis of airflow through experimental rural buildings: sensitivity to turbulence models", Biosyst. Eng., 97, pp.229-239 (2007)

12. T. Norton, J. Grant, R. Fallon, D.-W. Sun, "Optimising the ventilation configuration of naturally ventilated livestock buildings for improved indoor environmental homogeneity", Build. Environ., 45, pp. 983-995 (2010)

13. T. van Hoof, B. Blocken, "CFD evaluation of natural ventilation of indoor environments by the concentration decay method: $\mathrm{CO}_{2}$ gas dispersion from a semienclosed stadium", Build. Envir., 61, pp.1-17 (2013)

14. Y. Tominaga, B. Blocken, "Wind tunnel analysis of flow and dispersion in cross-ventilated isolated buildings: Impact of opening positions", J. Wind. Eng. Ind. Aerodyn., 155, pp. 74-88 (2016)

15. Y. Tominaga, B. Blocken, "Wind tunnel experiments on cross-ventilation flow of a generic building with contaminant dispersion in unsheltered and sheltered conditions", Build. Environ., 92, pp. 452-261 (2015)

16. ANSYS ${ }^{\circledR}$ FLUENT 18.0, www.ansys.com

17. M. Leschziner, Statistical Modelling for Fluid Dynamics - Demystified (Imperial College Press, London, 2015)

18. A.C. Benim, M. Geiger, S. Doehler, M. Schoenenberger, H. Roemer, "Modelling the flow in the exhaust hood of steam turbines under consideration of turbine-exhaust hood interaction", in: Proceed. 1st European. Conf. Turbomachinery - 
Fluid Dynamic and Thermodynamic Aspects: Computational. Methods, Erlangen, Germany, March 1-3, 1995, Book Series: VDI Berichte, Vol.1185, pp.343-357 (VDI Verlag, Duesseldorf, 1995)

19. J.L. Xia, B.L. Smith, A.C. Benim, J. Schmidli, G. Yadigaroglu, „Effect of inlet and outlet boundary conditions on swirling flows“, Computers \& Fluids, 26(8), pp.811-823 (1997)

20. A.C. Benim, M. Cagan, D. Gunes, "Computational analysis of transient heat transfer in turbulent pipe flow", International Journal of Thermal Sciences, 43(8), pp. 725-732 (2004)

21. H. Chattopadhyay, A.C. Benim, "Turbulent heat transfer over a moving surface due to impinging slot jets", Journal of Heat Transfer - Transactions of the ASME, 133(10), Article Nr.: 104502, 5 pages, doi:10.1115/1.4004075 (2011)

22. D.C. Wilcox, Turbulence Modeling for CFD, $3^{\text {rd }}$ Ed. (DCW Industries, La Canada, CA, 2006)

23. F.R. Menter, "Two-equation eddy-viscosity turbulence models for engineering applications", AIAA Journal, 32(8), pp.1598-1605 (1994)

24. A.C. Benim, A. Nahavandi, K.J. Syed, "URANS and LES analysis of turbulent swirling flows", Progress in Computational Fluid Dynamics - An International Journal, 5(8), pp. 444-454 (2005)

25. B.E. Launder, G.J. Reece, W. Rodi, "Progress in the development of a Reynolds-stress turbulence closure", J. Fluid Mech., 68(3), pp.537-566 (1975)

26. C.G. Speziale, S. Sarkar, T.B. Gatski, „Modelling the pressure-strain correlation of turbulence: an invariant dynamical systems approach", J. Fluid Mech., 227, pp.245-272 (1991)

27. P. Sagaut, Large Eddy Simulation for Incompressible Flows - An Introduction (Springer, Berlin, 2006)

28. E. Garnier, N. Adams, P. Sagaut, Large Eddy Simulation for Compressible Flows (Springer, Berlin, 2009)

29. F.F. Grinstein, L.G. Margolin, W.J. Rider, Implicit Large Eddy Simulation (Cambridge University Press, Cambridge, 2007)

30. A.C. Benim, H. Chattopadhyay, A. Nahavandi, "Computational analysis of turbulent forced convection in a channel with a triangular prism", International Journal of Thermal Sciences, 50(10), pp. 1973-1983 (2011)

31. A.C. Benim, M.P. Escudier, A. Nahavandi, A.K. Nickson, K.J. Syed, F. Joos, "Experimental and numerical investigation of isothermal flow in an idealized swirl combustor", International Journal of Numerical Methods for Heat \& Fluid Flow, 20(3), pp.348-370 (2010)

32. A.C. Benim, S. Iqbal. W. Meier, F. Joos, A. Wiedermann, "Numerical investigation of turbulent swirling flames with validation in a gas turbine model combustor", Applied Thermal Engineering, 110, pp.202-212 (2017)

33. B. Kader, "Temperature and Concentration Profiles in Fully Turbulent Boundary Layers", Int. J. Heat Mass Transfer, 24(9), pp.1541-1544, 1981.

34. B.E. Launder, N. Shima, "Second-Moment Closure for the Near-Wall Sublayer: Development and Application", AIAA J, 27(10), pp.1319-1325, 1989.

35. S.B. Pope, Turbulent Flows (Cambridge University Press, Cambridge, UK, 2000)

36. I.B. Celik, Z.N. Cehreli, I. Yavuz, "Index of Resolution Quality for Large Eddy Simulations", J. Fluids Engineering, 127, pp. 949-958 (2005)

37. P. Karava, T. Stathopulos, A.K. Athienitis, "Airflow assessment in cross-ventilated building with operable façade elements", Build. Environ., 46, pp. 266-279 (2011).

38. R.N. Meroney, "CFD prediction of airflow in buildings for natural ventilation", in: Proceedings of the $11^{\text {th }}$ Americas Conference on Wind Enginering, San Juan, Puerto Rico, pp. 1-11 (2009)

39. R. Ramponi, B. Blocken, "CFD simulation of crossventilation for a generic isolated building: Impact of computational parameters", Build. Environ., 53, pp. 34-48 (2012)

40. R. Ramponi, B. Blocken, "CFD simulation of crossventilation flow for different isolated building configurations: validation with wind tunnel measurements and analysis of physical and numerical diffusion effects", J. Wind. Eng. Ind. Aerodyn., 104-106, pp. 408-418 (2012)

41. Y. Tominaga, A. Mochida, R. Yoshie, H. Kataoka, T. Nozu, M, Yoshikawa, T. Shirasawa, "AIJ guidelines for practical applications of CFD to pedestrian wind environment around buildings" J. Wind Eng. Ind. Aerodyn., 9(10-11), pp. 1749-1761 (2008)

42. H. Schlichting, Boundary Layer Theory, $6^{\text {th }}$ ed., (McGraw-Hill, New York, USA, 1968) 